\title{
INVESTIGATION OF ANTIOXIDANT ACTIVITY (IN VITRO) AND GAS CHROMATOGRAPHY-MASS SPECTROMETRY PROFILING OF PORTULACA OLERACEA L. AND PORTULACA GRANDIFLORA HOOK. EXTRACTS
}

\author{
KINICHENKO AO* \\ Department of Pharmacognosy, Pharmacology and Botany, Zaporizhzhia State Medical University, Zaporizhzhia, Ukraine.
} Email: annetkinichenko@gmail.com

Received: 03 November 2018, Revised and Accepted: 18 December 2018

\section{ABSTRACT}

Objective: The aim of this research was to investigate the antioxidant activity (AOA) of the methanolic extracts of different parts of Portulaca oleracea and Portulaca grandiflora.

Methods: The plant different parts were extracted with methanol. The methanolic extracts of both species were screened for 2,2-diphenyl-1picrylhydrazyl radical scavenging abilities and researched by gas chromatography-mass spectrometry (GC-MS) analysis.

Results: GC-MS analysis of P. oleracea root extract revealed the presence of 39 biologically active compounds. 32 biologically active compounds were identified in P. grandiflora root extract. Both extracts revealed the AOA.

Conclusion: The results of the investigation could be useful for further pharmacological and phytochemical researches to assess the beneficial properties of both these species.

Keywords: Portulaca oleracea L., Portulaca grandiflora Hook., 2,2-Diphenyl-1-picrylhydrazyl method, Gas chromatography-mass spectrometry analysis.

(C) 2019 The Authors. Published by Innovare Academic Sciences Pvt Ltd. This is an open access article under the CC BY license (http://creativecommons. org/licenses/by/4. 0/) DOI: http://dx.doi.org/10.22159/ajpcr.2019.v12i3.30621

\section{INTRODUCTION}

Nature always stands as a golden mark to exemplify the outstanding phenomena of symbiosis. In the western world, as the people are becoming aware of the potency and side effect of synthetic drugs, there is an increasing interest in the natural product remedies with a basic approach toward the nature.

Natural products isolated from various sources, especially derived from plants, have long been used in the treatment of human ailments. Herbal medicines are also in great demand in the developed world for primary health care due to their efficacy, safety, and lesser side effects.

A number of scientific investigations have highlighted the importance and the contribution of many plant families used as medicinal plants. Plants have a large unexplored range of compounds, which is almost impossible to imitate, they will always remain a potential source of future drug discovery.

Search for new natural sources of biologically active compounds to obtain effective and safe drugs is one of the important problems of modern pharmacognosy. Accordingly, the source of good and safe natural raw materials can be genus Portulaca L. In Ukraine [1], the genus Portulaca L. is represented by two species such as Portulaca oleracea L. (Fig. 1) and Portulaca grandiflora Hook. (Fig. 2).

P. oleracea and P. grandiflora have been used in folk medicine since ancient times. $P$. oleracea possesses a wide spectrum of pharmacological properties such as neuroprotective, antimicrobial, antidiabetic, anti-inflammatory, antiulcerogenic, and anticancer activities [2-6]. P. grandiflora Hook. is a succulent plant. In oriental traditional medicine, $P$. grandiflora is used for the relief of a sore throat, skin rash, and detoxification [7].
The analysis of pharmacological and phytochemical researches for underground parts of the plants of genus Portulaca in Ukraine were not found to be reported earlier.

The aim of this investigation is to determine antioxidant activity (AOA) and to identify phytochemical compounds of underground parts of $P$. oleracea and P. grandiflora.

\section{METHODS}

\section{Collection of specimen}

The plants of $P$. oleracea and P. grandiflora were collected from Tomakivka district, Dnipropetrovs'k region, Ukraine. The plants were identified taxonomically and authenticated. The plants were dried in the shade. The dried plant material was powdered to a good powder using grinder mixer. The experimental samples taken for investigation were: P. oleracea root (POR), P. grandiflora root (PGR), P. oleracea herb, and $P$. grandiflora herb.

\section{Extraction of parts plants}

The dried plant parts were powdered to a good powder using grinder mixer. The plant powders were extracted with methanol (in the ratio of 1-10) at room temperature for about 3 days. The obtained mixture was filtered.

\section{Antioxidant analysis}

The 2,2-diphenyl-1-picrylhydrazyl (DPPH), free radical scavenging activity of methanolic extracts of the two plants, was determined using DPPH [8,9]. $0.5 \mathrm{ml}$ of different methanolic tinctures was mixed with $2.5 \mathrm{ml}$ of $0.1 \mathrm{mM}$ DPPH methanolic solution, and it was incubated for $30 \mathrm{~min}$ at the temperature of $25^{\circ} \mathrm{C}$ and optical density ( $\mathrm{A}_{\mathrm{s}}$ ) was measured at $517 \mathrm{~nm}$ by a spectrophotometer "ULAB 108UV." Ascorbic acid was used as the reference standard. Methanol was used as a blank. The experiment was carried out in triplicates. Weighing reagents and 
powdered samples of plants were conducted on electronic scales "ANG 200C."

AOA was calculated by the next formula:

$$
\operatorname{AOA}(\%)=\frac{\left(A_{D P P H}-A_{d}\right)}{A_{D P P H}} \times 100 \%
$$

In case of a negative meaning, AOA in percentage was estimated like 0 .

\section{Gas chromatography-mass spectrometry (GC-MS) analysis}

The methanolic extracts of different parts of the plants were performed on gas chromatograph "Agilent 7890B" with mass spectrometer detector 5977B. The capillary column was DB-5 ms $30 \mathrm{~m}$ in length, $250 \mu \mathrm{m}$ inner diameter, and $0.25 \mu \mathrm{m}$ film thickness. Helium was used as carrier gas at a constant flow rate of $1.3 \mathrm{ml} / \mathrm{min}$ with an injection volume of $0.5 \mu \mathrm{l}$ with an injector temperature of $265^{\circ} \mathrm{C}$. The oven temperature was programmed from an initial temperature of $70^{\circ} \mathrm{C}$ (isothermal for $1 \mathrm{~min}$ ), with an increase of $20^{\circ} \mathrm{C} / \mathrm{min}$ to $150^{\circ} \mathrm{C}$ (isothermal for $1 \mathrm{~min}$ ), and with an increase of $20^{\circ} \mathrm{C} / \mathrm{min}$ to $270^{\circ} \mathrm{C}$ (isothermal for $4 \mathrm{~min}$ ). The compounds were identified and authenticated using their MS data by compassion with those of the NIST14 mass spectral library.

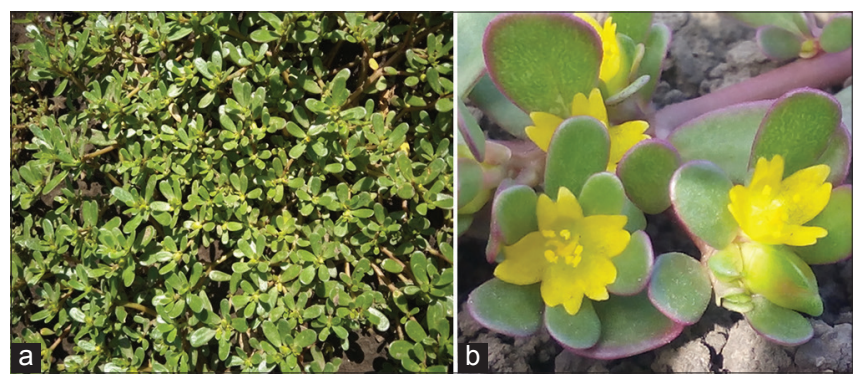

Fig. 1: (a and b) Portulaca oleracea

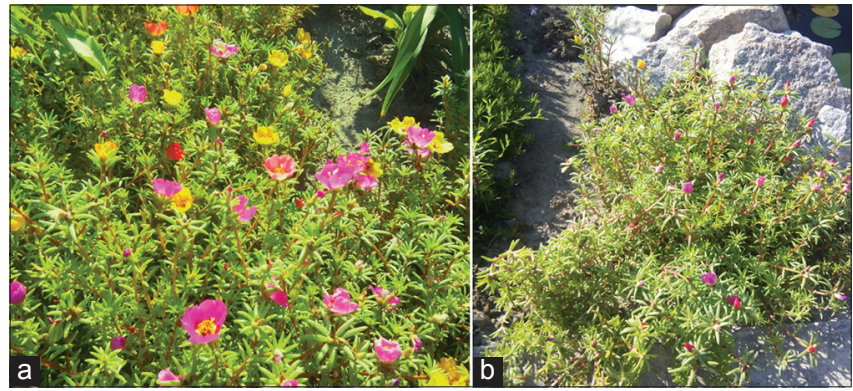

Fig. 2: (a and b) Portulaca grandiflora
The chemicals methanol, ascorbic acid, and DPPH were purchased from Sigma-Aldrich, USA [10].

\section{RESULTS AND DISCUSSION}

The DPPH radical scavenging analysis is considered to be a good in vitro model widely used to assess antioxidant efficacy of various types of a single compounds as well as of different plant extracts within a very short time. Furthermore, the DPPH method is considered as valid, accurate, and easy. DPPH is a stable and nitrogen-centered organic free radical and has strong absorption at $517 \mathrm{~nm}$ in alcoholic solution. The decentralized of the electron has the ability to increase violet color as evidence of the AOA. When DPPH solution is mixed with any type of antioxidants that have the ability to grant a hydrogen atom, this mixture will have the ability to reduce violet color as a sign of resistance to oxidative stress efficiently.

From the investigation, it is evident that the methanolic root extracts of both species possess effective AOA which may be due to the presence of respective phytocompounds. These phytocompounds may prevent the formation of new free-radical species and convert existing free radicals into less harmful molecules.

The antioxidant activities of plant extracts were researched to evaluate the promising directions of further pharmacological screening. Previous studies have reported that the aboveground part of $P$. oleracea is a rich source of natural antioxidants [11,12]. Aqueous juice of $P$. oleracea was screened for its AOA in adult male Waster albino rats. P. oleracea was caused a significant increase in glutathione reductase, glutathione peroxidase, and glutathione-S-transferase [13]. It was researched that mature plants of $P$. oleracea had higher total phenolic content and antioxidant activities than plants at the immature stages [14].

It was studied that $P$. oleracea polysaccharides had antioxidant effects on the oxidative injury in N-methyl-N'-nitro-N-nitrosoguanidine-induced gastric cancer rats [15]. No information has been published regarding the AOA of the underground part of P. oleracea and P. grandiflora.

It was established that PGR and POR extracts revealed the AOA (Fig. 3), which was comparable to the activity of reference standard (ascorbic acid). DPPH assay was done in dynamic. More expressed activity was characteristic for PGR extract, which inhibited the formation of free radicals at $89.3 \%$. POR extract inhibited the formation of the free radicals at $86.5 \%$. Plants of genus Portulaca could be useful for the prevention of cardiovascular, neurodegenerative, and other chronic diseases caused by oxidative stress.

\section{DPPH Assay}

It is famous, that herb, stems, leaves of genus Portulaca are a rich source of biologically active compounds, such as antioxidants and omega-3

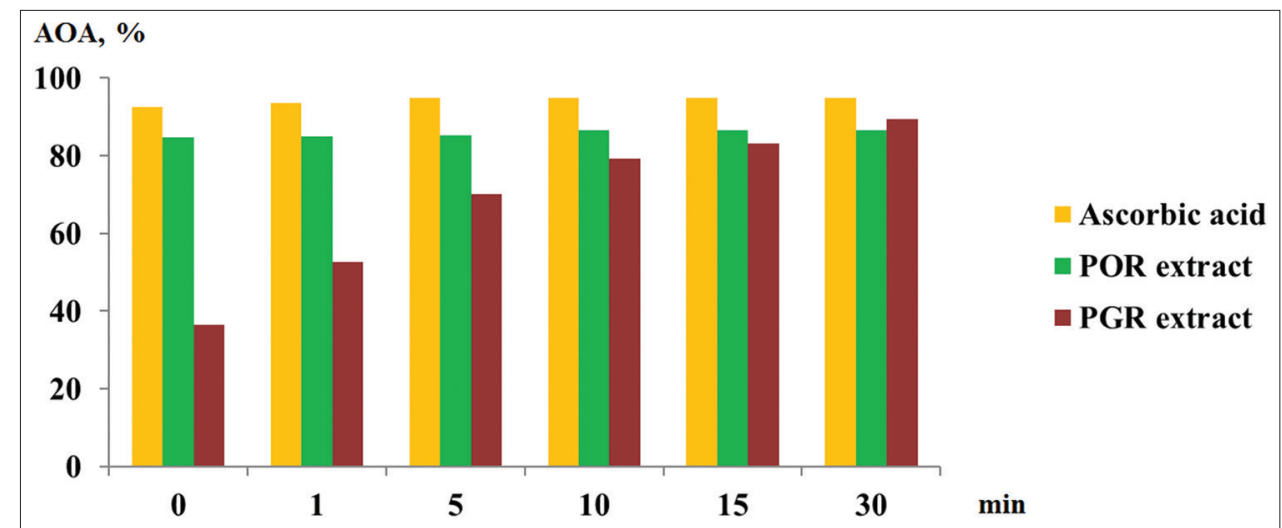

Fig. 3: Antioxidant activity data of plant extracts in dynamic (POR extract - Portulaca oleracea root extract; PGR extract - Portulaca grandiflora root extract; ascorbic acid is used as positive control. All the values were average of triplicates. The values were expressed in $\% \pm$ S.E.) 
Table 1: Identified biological active compounds using GC-MS analysis of the POR extract

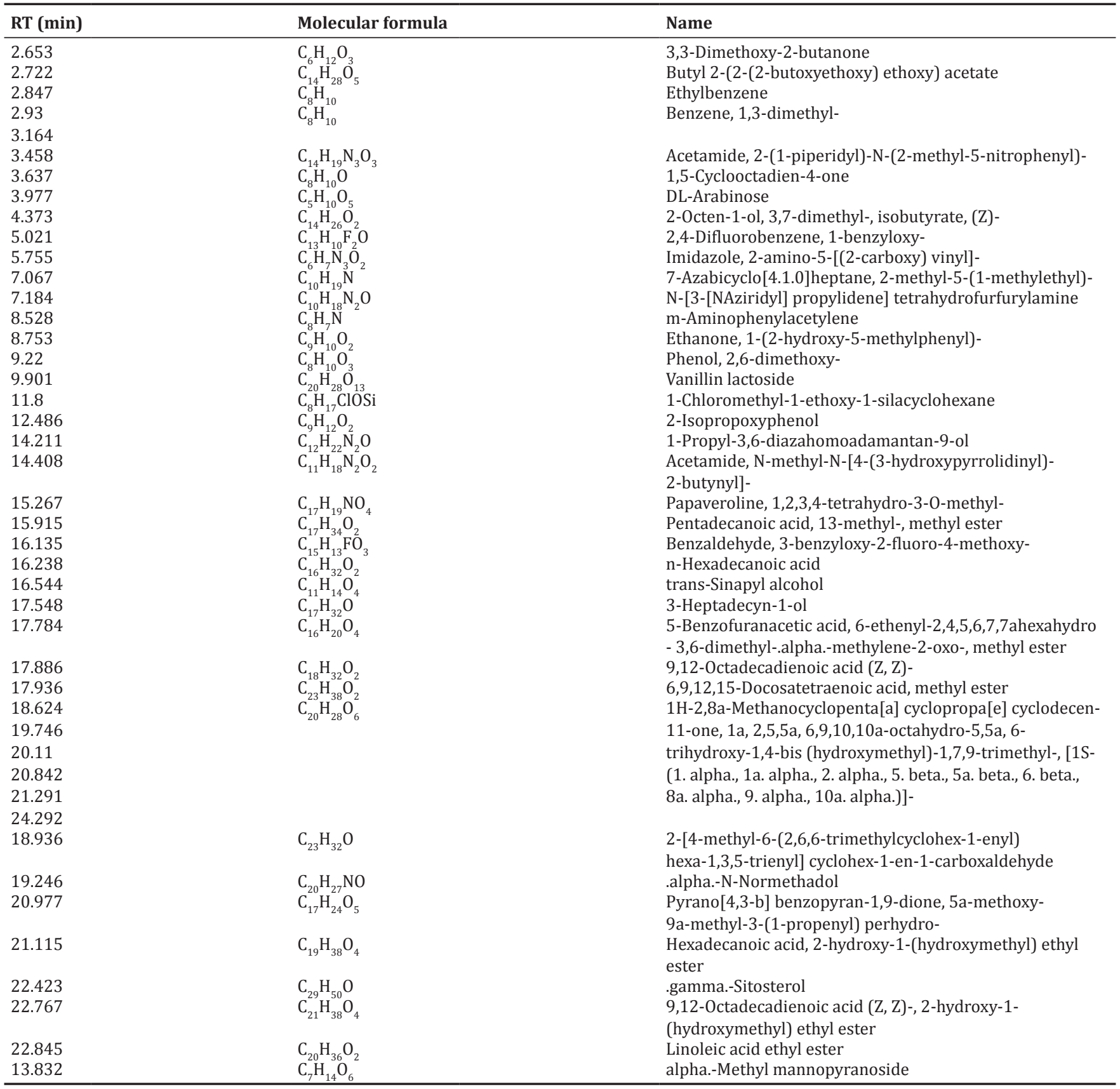

GCMS: Gas chromatographymass spectrometry, POR: Portulaca oleracea root

fatty acids. The phytochemical content of both extracts was screened by GC-MS method. The identification of phytochemical compounds was based on the retention time, molecular formula, and peak area. GC-MS analysis of POR extract revealed the presence of 39 biologically active compounds. The methanolic extract of $P$. oleracea was found alpha-Nnormethadol, DL-arabinose, methyl esters of fatty acids pentadecanoic acid, n-hexadecanoic acid, 9,12-octadecadienoic acid, ethyl esters linoleic acid, vanillin lactoside, gamma-sitosterol, and alpha-methyl mannopyranoside.

The GC-MS data obtained for the POR extract of various bioactive compounds are presented in Table 1 .

Thirty-two biologically active compounds were identified in PGR extract. The GC-MS analysis of the compounds carried out in PGR extract is shown in Table 2. The methanolic extract of P. grandiflora was found oleic acid, valeric acid, methyl esters of fatty acids n-hexadecanoic acid, vanillin lactoside, and gamma-sitosterol.

\section{CONCLUSION}

It was established that PGR and POR extracts revealed the AOA.

PGR and POR GC-MS analysis was not published earlier.

The results of the GC-MS analysis of extracts of underground parts of P. olerace a and P. grandiflora revealed the presence above 30 biologically active compounds such as polyunsaturated fatty acids, terpenoids, and phytosterols. Many new compounds were identified in the current investigation, which needs to be extensively studied. 
Table 2: Identified biological active compounds using GC-MS analysis of the PGR extract

\begin{tabular}{|c|c|c|}
\hline RT (min) & Molecular formula & Name \\
\hline 2.662 & $\mathrm{C}_{6} \mathrm{H}_{12} \mathrm{O}_{3}$ & 3,3-Dimethoxy-2-butanone \\
\hline 2.734 & $\mathrm{C}_{6}^{6} \mathrm{H}_{12} \mathrm{O}_{3}^{3}$ & 1,3-Dioxolane-4-methanol, 2-ethyl- \\
\hline 2.849 & $\mathrm{C}_{8}^{6} \mathrm{H}_{10}$ & Ethylbenzene \\
\hline 2.923 & $\mathrm{C}_{8}^{8} \mathrm{H}_{10}^{10}$ & Benzene, 1,3-dimethyl- \\
\hline \multicolumn{3}{|r|}{ - } \\
\hline 4.357 & $\mathrm{C}_{10} \mathrm{H}_{22}$ & Decane \\
\hline 4.855 & $\mathrm{C}_{7} \mathrm{H}_{8} \mathrm{O}$ & Benzyl alcohol \\
\hline 5.242 & $\mathrm{CH}_{4} \mathrm{~N}_{2} \mathrm{O}$ & Urea \\
\hline 5.369 & $\mathrm{C}_{11} \mathrm{H}_{21}^{2} \mathrm{ClO}_{2}$ & Valeric acid, 6-chlorohexyl ester \\
\hline 5.964 & $\mathrm{C}_{8} \mathrm{H}_{10}^{21} \mathrm{O}$ & Phenylethyl alcohol \\
\hline 6.163 & $\mathrm{C}_{17}^{8} \mathrm{H}_{27} \mathrm{~N}_{5} \mathrm{O}_{3}$ & $\begin{array}{l}\text { Pyrimidine-2,4,6-trione, 1-cyclohexyl-5-[(2-piperazin-1-yl- } \\
\text { ethylamino) methylene]- }\end{array}$ \\
\hline 7.171 & $\mathrm{C}_{12} \mathrm{H}_{26}$ & Dodecane \\
\hline 8.747 & $\mathrm{C}_{9} \mathrm{H}_{10}^{26} \mathrm{O}_{2}$ & Ethanone, 1-(2-hydroxy-5-methylphenyl)- \\
\hline 9.22 & $\mathrm{C}_{8}^{9} \mathrm{H}_{10} \mathrm{O}_{3}^{2}$ & Phenol, 2,6-dimethoxy- \\
\hline 9.887 & $\mathrm{C}_{20}^{0} \mathrm{H}_{28} \mathrm{O}_{13}$ & Vanillin lactoside \\
\hline 12.393 & $\mathrm{C}_{10}^{20} \mathrm{H}_{16}^{28} \mathrm{O}_{3}$ & $\begin{array}{l}\text { 1-(5-Methoxy-4,4-dimethyl-dihydro-furan-2-ylidene)- } \\
\text { propan-2-one }\end{array}$ \\
\hline 12.48 & $\mathrm{C}_{9} \mathrm{H}_{12} \mathrm{O}_{2}$ & Phenol, 4-propoxy- \\
\hline 13.374 & $\mathrm{C}_{7}^{3} \mathrm{H}_{14} \mathrm{O}_{6}^{2}$ & Myo-inositol, 4-C-methyl- \\
\hline 14.211 & $\mathrm{C}_{12}^{1} \mathrm{H}_{22} \mathrm{~N}_{2} \mathrm{O}$ & 1-Propyl-3,6-diazahomoadamantan-9-ol \\
\hline 14.408 & $\mathrm{C}_{11}^{12} \mathrm{H}_{18}^{22} \mathrm{~N}_{2}^{2} \mathrm{O}_{2}$ & $\begin{array}{l}\text { Acetamide, N-methyl-N-[4-(3- } \\
\text { hydroxypyrrolidinyl)-2-butynyl]- }\end{array}$ \\
\hline 14.524 & $\mathrm{C}_{13} \mathrm{H}_{18} \mathrm{O}_{3}$ & $\begin{array}{l}\text { 2-Cyclohexen-1-one, 4-hydroxy-3,5,5-trimethyl-4- } \\
\text { (3-oxo-1-butenyl)- }\end{array}$ \\
\hline 16.237 & $\mathrm{C}_{16} \mathrm{H}_{32} \mathrm{O}_{2}$ & n-Hexadecanoic acid \\
\hline 16.544 & $\mathrm{C}_{11} \mathrm{H}_{14} \mathrm{O}_{4}$ & trans-Sinapyl alcohol \\
\hline 17.945 & $\mathrm{C}_{18} \mathrm{H}_{34} \mathrm{O}_{2}$ & Oleic acid \\
\hline 20.875 & $\mathrm{C}_{29}^{18} \mathrm{H}_{34}^{34} \mathrm{~N}_{2}^{2} \mathrm{O}_{3}$ & $\begin{array}{l}\text { Benzoic acid, 4-(4-butylcyclohexyl)-, 4-butoxy- } \\
\text { 2,3-dicyanophenyl ester }\end{array}$ \\
\hline 21.083 & $\mathrm{C}_{21} \mathrm{H}_{31} \mathrm{NO}_{3}$ & $\begin{array}{l}\text { Phenanthrene-1-acetaldehyde, 7-acetoxy-2.beta.- } \\
\text { cyano-2,4b-dimethyl- }\end{array}$ \\
\hline 21.735 & $\mathrm{C}_{16} \mathrm{H}_{18} \mathrm{~N}_{8} \mathrm{~S}_{2}$ & Benzene, 1,3-bis (1-allyl-5-tetrazolylthiomethyl)- \\
\hline 21.806 & $\mathrm{C}_{28} \mathrm{H}_{48} \mathrm{O}$ & $\begin{array}{l}\text { Cholest-14-en-3-ol, 4-methyl-, } \\
\text { (3. beta., 4. alpha., 5. alpha.)- }\end{array}$ \\
\hline 21.957 & $\mathrm{C}_{20} \mathrm{H}_{28} \mathrm{O}_{6}$ & 1H-2,8a-Methanocyclopenta[a] cyclopropa[e] \\
\hline 23.265 & & $\begin{array}{l}\text { cyclodecen-11-one, 1a, 2,5,5a, 6,9,10,10a-octahydro-5,5a, } \\
\text { 6-trihydroxy-1,4-bis (hydroxymethyl)-1,7,9-trimethyl-, } \\
\text { [1S-(1. alpha., 1a. alpha., 2. alpha., 5. beta., } 5 \text { a. beta., } \\
\text { 6. beta., 8a. alpha., 9. alpha., 10a. alpha.)]- }\end{array}$ \\
\hline 20.977 & $\mathrm{C}_{17} \mathrm{H}_{24} \mathrm{O}_{5}$ & $\begin{array}{l}\text { Pyrano[4,3-b] benzopyran-1,9-dione, 5a-methoxy- } \\
\text { 9a-methyl-3-(1-propenyl) perhydro- }\end{array}$ \\
\hline 21.115 & $\mathrm{C}_{19} \mathrm{H}_{38} \mathrm{O}_{4}$ & $\begin{array}{l}\text { Hexadecanoic acid, 2-hydroxy-1- } \\
\text { (hydroxymethyl) ethyl ester }\end{array}$ \\
\hline 22.425 & $\mathrm{C}_{29} \mathrm{H}_{50} \mathrm{O}$ & Gamma.-sitosterol \\
\hline 23.633 & $\mathrm{C}_{16} \mathrm{H}_{14} \mathrm{ClN}_{3} \mathrm{O}$ & Chlordiazepoxide \\
\hline
\end{tabular}

GC-MS: Gas chromatography-mass spectrometry, PGR: Portulaca grandiflora root

Thus, P. oleracea and P. grandiflora are promising medicinal plants with beneficial biological active compounds and require further pharmacological and phytochemical investigations.

\section{ACKNOWLEDGMENT}

The author would like to expend her gratitude toward the Department of Organic and Bioorganic Chemistry and the Department of Toxicological and Inorganic Chemistry, Zaporizhzhia State Medical University.

\section{AUTHORS' CONTRIBUTIONS}

This work was done by the author named in this article and all liabilities pertaining to claims relating to the content of this article will be borne by the author. The review of literature, collection of plant material, preparation of extracts, data collection and analysis, and drafting of the manuscript were done by Ms. Kinichenko AO.

\section{CONFLICTS OF INTEREST}

The author has no conflicts of interest in this study.

\section{REFERENCES}

1. Hrodzynskyi AM. Medicinal Plants: Encyclopedic Guide. Kyiv: Ukrainian Encyclopedia MP Bazhana; 1990.

2. Wasnik DD, Tumane PM. Preliminary phytochemical screening and evaluation of antibacterial activity of Portulaca oleracea. World J Pharm Res 2014;3:920-32.

3. Azuka OI, Mary BA. A review on Portulaca oleracea (Purslane) plant its nature and biomedical benefits. J Biomed Mater Res 2014;5:75-80.

4. Zhao R, Zhang T, Ma B, Li X. Antitumor activity of Portulaca oleracea L. Polysaccharide on heLa cells through inducing TLR4/NF$\kappa B$ signaling. Nutr Cancer 2017;69:131-9.

5. Gu JF, Zheng ZY, Yuan JR, Zhao BJ, Wang CF, Zhang L, et al. Comparison on hypoglycemic and antioxidant activities of the fresh and dried Portulaca oleracea L. In insulin-resistant hepG2 cells and streptozotocin-induced C57BL/6J diabetic mice. J Ethnopharmacol 2015;161:214-23.

6. Al-Sheddi ES, Farshori NN, Al-Oqail MM, Musarrat J, Al-Khedhairy AA, Siddiqui MA, et al. Portulaca oleracea seed oil exerts cytotoxic effects on human liver cancer (HepG2) and human lung cancer (A-549) cell lines. Asian Pac J Cancer Prev 2015;16:3383-7.

7. Ashok KJ, Mudasir B. Efficient micropropagtion protocol for Portulaca 
grandiflora Hook. Using shoot tip explants. N Y Sci J 2010;3:112-6.

8. Kazunin MS, Voskoboynik OY, Nosulenko IS, Berest GG, Sergeieva T, Okovytyy S, et al. Synthesis, tautomerism, and antiradical activity of novel pteridinetrione derivatives. J Heterocycl Chem 2018;5:1033-41.

9. Sreedevi P, Vijayalakshmi K. Determination of antioxidant capacity and gallic acid content in ethanolic extract of Punica granatum L. Leaf. Asian J Pharm Clin Res 2018;11:319-23.

10. Hasan HT, Kadhim EJ. Phytochemical investigation of leaves and seeds of Corchorus olitorius L. cultivated in Iraq. Asian J Pharm Clin Res 2018;11:408-17.

11. Mousavi SR, Niazmand R, Noghabi MS. Antioxidant activity of purslane (Portulaca oleracea L.) seed hydro-alcoholic extract on the stability of soybean oil. J Agric Sci Tech 2015;17:1473-80.

12. Erkan N. Antioxidant activity and phenolic compounds of fraction from Portulaca oleracea L. Food Chem 2012;133:775-81.

13. Dkhil MA, Moniem AE, Al-Quraishy S, Saleh RA. Antioxidant effect of purslane (Portulaca oleracea) and its mechanism of action. J Med Plant Res 2011;5:1563-89.

14. Uddin MK, Juraimi AS, Ali ME, Ismail MR. Evaluation of antioxidant properties and mineral composition of purslane (Portulaca oleracea L.) at different growth stages. Int J Mol Sci 2012;13:10257-67.

15. Li Y, Hu Y, Shi S, Jiang L. Evaluation of antioxidant and immunoenhancing activities of purslane polysaccharides in gastric cancer rats. Int J Biol Macromol 2014;68:113-6. 